\title{
Education for practitioners and patients
}

\author{
Ruby A Singh ${ }^{1}$, Maurice C McGrath ${ }^{2}$
}

1. New Delhi, India

2. Senior Editor, AMJ.

\section{EDITORIAL}

Please cite this paper as: Singh RA, McGrath MC. Education for practitioners and patients. AMJ 2013, 6, 12, 724-726. http//dx.doi.org/10.4066/AMJ.2013.1952

\section{Corresponding Author:}

Ruby A Singh

D-3/3288 Vasant Kunj, New Delhi-110070, India

Email: ruby_a_singh@hotmail.com

The goal for patients and practitioners alike is to be the recipients and providers of 'best practice'. This paradigm was encompassed in the 'Sicily statement on evidencebased practice'. ${ }^{1}$ At the heart of the statement lies the explicit collaboration of patients and practitioners in decisions about healthcare. Such important collaboration takes the form of patients being informed by the 'tacit and explicit knowledge of those providing care, within the context of available resources', founded on the 'best available, current, valid and relevant evidence'. Patient involvement in clinical decision-making is viewed as a key part of the process of being an effective practitioner.

Emerging as key to successful patient collaboration is 'health literacy', which is defined as 'the degree to which individuals can obtain, process, and understand the basic health information and services they need to make appropriate health decisions'. ${ }^{2}$ Low health literacy is perceived as an impediment to health and it appears to be associated with poor health outcomes. In their updated (2011) systematic review of health literacy interventions and outcomes The Agency for Healthcare Research and Quality identified moderate evidence that suggested lower health literacy was associated with increased hospitalization, greater emergency care use, lower use of mammography, and lower receipt of influenza vaccine. ${ }^{2}$ This systematic review also cautiously identified numeracy to be more highly correlated with health outcomes than health literacy.

The emergence of such insights, and dare one say 'imperatives', bear mightily on effective patient care and excellent outcomes. In their therapeutic collaboration, patients and practitioners engage in a two-way educating dialogue, a process vital to both realising their respective goals. The word dialogue has been chosen deliberately because stemming from a Greek root it is described as a 'flow of meaning between or among a number of people'. ${ }^{3}$ It is considerably more than mere talk and it is far removed from the bare 'interrogation' of a patient. It embodies the essence of a present-day practitioner imperative that aspires to excellence of patient communication.

There never is, never has been, and never will be an 'end' to medical learning. It is of necessity a life-long engagement born of research and the noble quest to simply and persistently 'do better'. Medical and surgical advances, advances in technology, communication and pharmaceuticals, all these and more contribute to the omnipresent educational drive.

The Health Assembly at the $\mathrm{WHO}^{4}$ stressed, 'the importance of reorientation of the education and practice of health care providers'. Highlighting this need, one assessment of the Eastern Mediterranean region ${ }^{5}$ identified short-comings, stating: 'education programmes are not linked to the needs of the country. Curricula are designed without reference to national health care plans or the needs of the population. Professional education focuses more on curative hospitalbased care and less on preventive and community oriented care. Too little attention is given to continuing education, training is inadequate and unfocused, quality and skill sets lacking'.

A similar opinion has been expressed regarding medical education in India. ${ }^{6}$ Despite having the highest number of medical colleges in the world, basic, quality health care is lacking due to lack of resources and suitable infrastructure. A plan for 'Health for all by 2020 ' has been developed, but it needs to be supported by concurrent innovations in medical education such as self-directed learning, critical thinking and research abilities. Foundation courses, a multi-disciplinary approach and early clinical exposure will be structured to motivate and prepare future practitioners for the challenges of the changing health care system. Institutions will also be 
obliged to demonstrate accountability and responsibility in their role. ${ }^{7}$

In facilitating education, both patient and practitioner education are benefitting from new, 'smart' technologies. A literature search on the use of smartphones in medicine yielded a wealth of information. The potential is only just beginning to be tapped for education, testing, evaluation and diagnostics. ${ }^{8}$ One study showed an increasing trend of smartphone usage among medical students and practitioners ${ }^{9}$ with between one and five medical related applications or 'apps' on their iPhones being utilised for up to 30 minutes in a 24 hour period. Students preferred to use the disease diagnosis/management and drug reference apps while the doctors favoured the clinical score/calculator apps. Elsewhere in Peru, smartphones were rigged to access a set of 3D learning scenarios simulating interactive clinical cases of HIV. ${ }^{10}$ A group of HIV specialists was also available for discussion and clarifications. Learning outcomes were tracked and verified using quizzes with multiple-choice questions. 'Training, supervision and clinical mentoring of health workers were the cornerstone of the scaling up process of HIV/AIDS care in resource-limited settings (RLSs). Educational modules on mobile phones can give flexibility to health care workers (HCWs) for accessing learning content anywhere'. $^{10}$ The YeastGenome app has made the Saccharomyces Genome Database available on Apple iPhones and iPads. Yet another study determined that the pre-procedural use of a smartphone neonatal intubation instructional application (NeoTube) improved trainee knowledge and enhanced procedural skills performance in newborn intubation. ${ }^{11}$

However, with progress comes the developing awareness that with many healthcare apps involving diagnosis and patient management, there appears a need to exercise caution. Regulation by the US Food and Drug Administration is being seen as a desirable quality verification process for an app before release. ${ }^{12}$

McManus $^{13}$ has made the argument to train primary health care $(\mathrm{PHC})$ practitioners in health promotion and to use innovative e-processes in order to 'streamline the treatment process and improve patient outcomes'. Population-based health education campaigns conceived and coordinated by PHC practitioners have resulted for example in a reduction of reported tobacco use among Australian adults from 35 per cent in 1980 to 23 per cent in $2001 .^{14}$ Similar PHC educative interventions including the counselling of youngsters for alcohol and drug abuse, the practice of safe sex, awareness of blood pressure, body mass index values, the multiple benefits of exercise.
Effective communication paves the way for a dynamic, collaborative and supportive interaction between a practitioner and their community. ${ }^{15}$ The development of a shared language needs constant work where awareness and education are needed to maintain it. ${ }^{16}$ Effective communication is an acquired skill with the potential to usefully impact patient satisfaction and health outcomes. Cultural competence and communication already play a part in many healthcare curricula. Medical professionals and students realise the importance of communication and want it incorporated into the medical curriculum. ${ }^{17}$

The increased use of the internet plays a central role making a convenient channel for disseminating information to the community. ${ }^{18}$ Saini et al. highlighted the role of both the pharmacists and the patients in asthma management. ${ }^{19}$ Pharmacists, being readily accessible, can be relied upon for delivery of self-management education and repeated inhaler technique interventions. The Australian National Asthma Management Handbook suggests that selfmanagement engages patients and allows them to troubleshoot and solve problems. It thus promotes patient autonomy and independence. Unsurprisingly, it was both a well received and highly successful initiative.

\section{Conclusion}

The role of practitioner and patient education has morphed into a collaborative imperative upon which the wider effectiveness of evidence based practice rests. The process of and accessibility to education has not only been vastly facilitated by technology, it has led to an explosion of information for all. Despite of these colossal changes, 'the gap between what we know and what we aim for persists. ${ }^{20}$ In reality, this gap will never be closed. It will however continue to provide the impetus and the motivation for patient and practitioner alike to ever engage in the dialogue of education.

\section{References}

1. Dawes M, Summerskill W, Glasziou P, Cartabellotta A, Martin J, Hopayian K, Porzolt F, Burls A, Osborne J. Sicily statement on evidence-based practice. BMC Med Educ. 2005;5(1). Doi:10.1186/1472-6920-5-1.

2. Berkman ND, Sheridan SL, Donahue KE, Halpern DJ, Viera A, Crotty K, Holland A, Brasure M, Lohr KN, Harden E, Tant E, Wallace I, Viswanathan M. Health Literacy Interventions and Outcomes: An Updated Systematic Review, Executive Summary, Evidence Report/Technology Assessment: Number 199. AHRQ Publication Number 11-E006-1, March 2011. Agency for Healthcare Research and Quality, Rockville, MD.

http://www.ahrq.gov/clinic/epcsums/litupsum.htm 
3. Jaworski J. Synchronicity: the inner path of leadership. Ed. Flowers BS. Berrett-Koehler: San Francisco 1996. pp.13

4. Reorienting medical education and medical practice for health for all. Geneva: World Health Organization; 1995 (resolution WHA48.8). Available at: http://www.who.int/hrh/resources/WHA48-8_EN.pdf

5. Alwan A, Hornby P. The implications of health sector reform for human resources development. Bull World Health Organ. 2002;80(1):56-60.

6. Shrivastava SRBL, Shrivastava PS, Ramasamy J. Int J Prev Med. 2013;4(8):980-981.

7. Busari JO. Comparative analysis of quality assurance in health care delivery and higher medical education. Adv Med Educ Pract. 2012;3:121-127. Doi: 10.2147/AMEP.S38166.

8. Wadhawan $T$, Situ N, Rui $H$, Lancaster $K$, Yuan $X$, Zouridakis G. Implementation of the 7-point checklist for melanoma detection on smart hand held devices. Conf Proc IEEE Eng Med Biol Soc. 2011;3180-3183.

9. Payne KB, Wharrad H, Watts K. Smartphone and medical related app use among medical students and junior doctors in the United Kingdom (UK): a regional survey. BMC Med Inform Decis Mak. 2012;12:121.

10. Zolfo M, Iglesias D, Kiyan C, Echevarria J, Fucay L, Llacsahuanga E, de Waard I, Suàrez V, Castillo Llaque W, Lutgarde L. Mobile learning for HIV/AIDS healthcare worker training in resource-limited settings. AIDS Res Ther. 2010;7:35.

11. Hawkes CP, Walsh BH, Ryan CA, Dempsey EM. Smartphone technology enhances newborn intubation knowledge and performance amongst paediatric trainees. Resuscitation. 2013;84(2):223-226.

12. Moodley A, Mangino JE, Goff DA. Review of Infectious Diseases Applications for iPhone/iPad and Android: From Pocket to Patient. Clin Infect Dis. 2013;57(8):1145-1154.

13. McManus A. Health promotion innovation in primary health care. Australas Med J. 2013;6(1):15-18.

14. White V, Hill D, Siahpush M, Bobevski I. How has the prevalence of cigarette smoking changed among Australian Adults? Trends in smoking prevalence between 1980 and 2001. Tob Control. 2003;1Suppl2:ii67-74.

15. Doctor-Patient Communication: Principles and Practices. Kurtz SM. Available at: http://www.bradfordvts.co.uk/wpcontent/onlineresources/0200consultation/communication \%20-\%20principles\%20and\%20practices.pdf

16. Thomas J, McDonagh D. Shared language: Towards more effective communication. Australas Med J. 2013;6(1):46-54. 17. Shankar PR, Dubey AK, Balasubramanium R, Dwivedi NR. Student attitude towards communication skills learning in a Caribbean medical school. Australas Med J. 2013;6(9):466475.
18. Fraval A, Chong YM, Holcdorf D, Plunkett V, Tran P. Internet use by orthopaedic outpatients-current trends and practices. Australas Med J. 2012;5(12):633-638.

19. Saini B, Krass I, Smith L, Bosnic-Anticevich S, Armour C. Role of community pharmacists in asthma- Australian research highlighting pathways for future primary care models. Australas Med J. 2011;4(4):190-200.

20. Gawande A, In: Complications: A Surgeon's Notes on an Imperfect Science. Picador 2003.

\section{ACKNOWLEDGEMENTS}

RS thanks the AMJ for inviting her to contribute to this editorial.

\section{CONFLICTS OF INTEREST}

MCM is a Senior Editor for the AMJ.

\section{PEER REVIEW}

Commissioned. Internally reviewed. 